\title{
Reverse-Loop Upper Arm Arteriovenous Graft for Chronic Hemodialysis
}

\author{
Wen-Shin Yang, ${ }^{*}$ Tzu-Chun Chen, $†$ Jer-Shen Chen, $\ddagger$ and Chih-Yang Chan $¥ \S$ \\ *Renal Department, Singapore General Hospital, Singapore, †Division of Cardiovascular Surgery, Min-Sheng \\ General Hospital, Tao-Yuan, Taiwan, キDivision of Cardiovascular Surgery, Far Eastern Memorial Hospital, \\ Banqiao, Taiwan, and §Department of Surgery, National Taiwan University Hospital, Taipei, Taiwan
}

\begin{abstract}
Options for an upper arm arteriovenous graft (AVG) commonly include the placement of a straight prosthetic graft connecting the brachial artery to the axillary vein. However, such configuration leads to underutilization of the upper arm veins, resulting in the loss of venous capital in the upper arm for future secondary fistula creation. In this retrospective analysis, we evaluated seven patients who had upper-arm AVGs created in a reverse-loop configuration. The prosthetic graft was created by connecting the brachial artery close to the cubital fossa and tunneled subcutaneously in a looped fashion distally thereby connecting the basilic or deep brachial vein just above the elbow. Endpoints were interventions, thrombosis, and loss of access at the last examination. The brachial vein was used in two patients and the basilic vein in the other five. The median duration of follow-up with $100 \%$

patency of the AVGs was 10.0 (range, 3.0-25.0) months. Patients were able to achieve a target hemodialysis dose with a $\left(K_{\text {urea }} \times t_{\mathrm{d}}\right) / V_{\text {urea }}$ value of 1.4 (range, 1.2-1.5). The median flow rates achieved were 205.0 (range, 203.3-236.7) and 266.7 (range, 203.3-276.7) $\mathrm{ml} /$ minute at the first and 3-month dialysis sessions, respectively. The median dialysis venous pressures were 128.0 (range, 108.3-178.0) and 131.0 (range, 116.7148.7) $\mathrm{mmHg}$ at the first and third month after operation, respectively. The median peak systolic velocity ratios of artery-graft and vein-graft junctions were 2.1 (range, 1.4-2.4) and 3.0 (range, $2.3-3.8$ ) cm/second, respectively. In conclusion, this is a logical approach for patients who have exhausted their forearm vessels for AVG creation. In addition, it also provides a platform for future creation of a secondary fistula in the upper arm.
\end{abstract}

In patients with end-stage renal disease that require chronic intermittent hemodialysis, the maintenance of adequate vascular access is very important. Arteriovenous fistulas constructed from autogenous upper extremity veins are the access method of choice as they offer the best patency and lowest complication rates (1). Repeated fistula construction at different levels of the upper extremity (wrist, forearm, upper arm) is often required and can ultimately lead to exhaustion of autogenous vascular access sites. A prosthetic arteriovenous graft (AVG) on the upper arm is a common hemodialysis access site in uremic patients when the forearm vessels are compromised (2). Although an autogenous arteriovenous fistula is the access method of choice, there remains a small group of patients who require the placement of an AVG (3). A meta-analysis of several clinical trials reported that the primary patency rate of an AVG on the upper arm in 431 patients was $69 \%$ at 6 months and $49 \%$ at 18 months (1). Conventional configurations

Address correspondence to: Chih-Yang Chan, MD, PhD, Department of Surgery, National Taiwan University Hospital, 10002, No. 7 Chung San South Road, Taipei, Taiwan, or e-mail: chanchihyang@gmail.com.

Seminars in Dialysis-Vol 22, No 6 (November-December) 2009 pp. 684-687

DOI: $10.1111 /$ j. 1525-139X.2009.00639.x

(c) 2009 Wiley Periodicals, Inc. of an AVG on the upper arm include straight, curved, and loop configurations $(4,5)$. These configurations very often require a segment of the upper arm vessels to be bypassed, resulting in venous wastage. The objective of the present study was to report our experience of constructing a reverse-loop upper arm AVG using the most distal brachial vessels, thus ensuring maximum venous real estate for future access.

\section{Materials and Methods}

We reviewed the records of all patients who had a reverse-loop AVG constructed in the last 2 years. These patients had failed forearm or elbow vascular access previously and had unsuitable forearm vessels. Demographic data, preoperative factors, and outcomes were collected through retrospective chart review. The procedures, including obtaining informed consent, were conducted in accordance with the ethical standards of the Helsinki Declaration. Surgery was conducted in the conventional manner through a $3-$ to $5-\mathrm{cm}$ oblique incision made $1 \mathrm{~cm}$ proximal to the elbow. Connecting vessels were identified. The deep brachial vein was used as the outflow vein if the basilic vein was deemed unsuitable. All AVGs were connected at the arterial end to the brachial artery. We placed a standard 6-mm diameter polytetrafluoroethylene graft (IMPRA Carboflow; Bard 
Peripheral Vascular, Inc., Tempe, AZ) subcutaneously, and reverse-looped the graft around the biceps margins via one or two counter incisions (Fig. 1). The AVG was not cannulated until 3-4 weeks after creation. Target hemodialysis flow rates were $200 \mathrm{ml} /$ minute for the first session and $250 \mathrm{ml} /$ minute for subsequent regular sessions. The hemodialysis dose was expressed as $\left(K_{\text {ur- }}\right.$ ea $\times t \mathrm{~d}) / V_{\text {urea }}(K t / V)$ (6). Preoperative factors and procedural complications were categorized and graded according to the Society for Vascular Surgery/American Association for Vascular Surgery reporting standards $(5,7)$. Follow-up measures included hemodialysis parameters at the first session and at 3-months. Duplex ultrasound scans of the graft and junctions were performed when indicated. Endpoints were interventions, thrombosis, and loss of access at the last examination.

\section{Statistical Analysis}

Data were presented as median (range) for continuous variables and number (percentage) for categorical variables. Events were defined as the development of any acute complications such as stenosis, thrombosis, or malfunction requiring intervention during the follow-up period. All statistical analyses were performed with SPSS software (Version 15.0, SPSS Inc., Chicago, IL).

\section{Results}

From March 2005 through May 2007, four men and three women with reverse-loop AVGs were included. Among seven patients with reverse-loop AVGs, five patients had operations to connect the basilica vein with the brachial artery and two patients had operations to connect the deep brachial vein with the brachial artery.

The demographics and clinical diagnosis are summarized in Table 1. The median age of the patients was 69.0

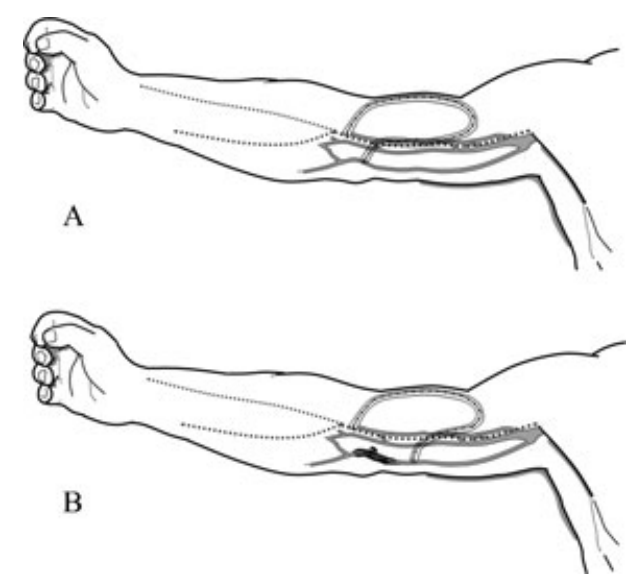

FIg. 1. Drawing of a reverse-loop upper arm arteriovenous graft. (A) Placement around the lateral margin of the biceps muscle allows easy cannulation. (B) When intimal hyperplasia produces severe stenosis of the graft-venous junction, the junction can be improved by the creation of a new proximal anastomosis. Repeat revision, conversion to a curved graft, or placement of a new graft can be performed as needed. (range, 37.0-81.0) years. The median body mass index and body surface area were 24.0 (range, 17.5-26.0) $\mathrm{kg} / \mathrm{m}^{2}$ and 1.5 (range, 1.4-1.7) $\mathrm{m}^{2}$, respectively. The median duration of follow-up was 10.0 (range, 3.0-32.0) months and the median event-free survival time was 10.0 (range, 3.0-25.0) months. The patients with this reverseloop AVG were able to achieve the target hemodialysis dose with a median $K t / V$ value of 1.4 (range, $1.2-1.5$ ). The median flow rate was 205.0 (range, 203.3-236.7) $\mathrm{ml} /$ minute at the first month after the operation and 266.7 (range, 203.3-276.7) $\mathrm{ml} /$ minute at the third month after operation. The median dialysis venous pressure at the first month was 128.0 (range, 108.3-178.0) $\mathrm{mmHg}$ and 131.0 (range, 116.7-148.7) $\mathrm{mmHg}$ at the third month after operation. Duplex ultrasound scan measurements were available in six patients. The median peak systolic velocity ratios of artery-graft and veingraft junctions were 2.1 (range, 1.4-2.4) and 3.0 (range, $2.3-3.8) \mathrm{cm} / \mathrm{second}$, respectively.

The factors related to outcomes are presented in Table 2. Among the seven patients evaluated, seven $(100 \%)$ had prior procedures on same limb, two $(28.6 \%)$ used tobacco, two (28.6\%) had lung disease, two $(28.6 \%)$ had cerebral vascular accidents, and five $(71.4 \%)$ had coronary artery disease. There were three $(42.9 \%)$ patients who had diabetes, seven $(100.0 \%)$ who had hypertension, and five (71.4\%) who had hyperlipidemia.

Table 2 also presents the grading severity of complications. Among the seven patients, five (71.4\%) developed stenosis, one $(14.3 \%)$ developed a hematoma, three $(42.9 \%)$ developed thrombosis, and three (42.9\%) developed sensory neuropathy.

Among the five patients who developed stenosis, patients 4 and 7 had grafts that were considered stenotic because of peak systolic velocity $>400 \mathrm{~cm} /$ second and patient 3 needed percutaneous transluminal angioplasty repeated at frequent intervals. In patient 6 , who developed thrombosis, the first thrombosis was treated by thrombectomy, and the second thrombosis was treated by revising the venous anastomosis (the outflow portion of graft was moved proximally on the vein; Fig. 1B). Patients 1 and 7 with thrombosis were treated by revising the venous anastomosis (the outflow portion of graft was moved proximally on the vein). Patient 1 received a new AVG construction on the same upper arm after two episodes of thrombosis. Three patients (patients 1, 3, and 5) experienced mild sensory neuropathy.

\section{Discussion}

The results of our case series demonstrate that a reverse-loop AVG placed above the elbow is a feasible configuration for dialysis access. Such efficient use of venous real estate maximizes the availability of the upper limb for future dialysis access including the creation of secondary fistulae. In such a setting, we were able to conserve vessels for future access by using the same outflow vein when revision or new placement was required. This could be achieved by moving a short distance proximally along the vein during each subsequent surgical interven- 
TABLE 1. Demographics and clinical diagnosis

\begin{tabular}{|c|c|c|c|c|c|c|c|c|}
\hline & \multirow[b]{2}{*}{$N(\%) /$ Median (range) } & \multicolumn{7}{|c|}{ Patient no. } \\
\hline & & 1 & 2 & 3 & 4 & 5 & 6 & 7 \\
\hline Reverse-loop AVG connection (DB) & $5(71.4)$ & B & DB & $\mathrm{B}$ & $\mathrm{B}$ & B & B & DB \\
\hline Gender (male) & $4(57.2)$ & M & $\mathrm{F}$ & M & M & $\mathrm{F}$ & $\mathrm{F}$ & M \\
\hline Age (years) & $69.0(37.0-81.0)$ & 69 & 49 & 37 & 69 & 81 & 68 & 71 \\
\hline $\mathrm{BMI}\left(\mathrm{kg} / \mathrm{m}^{2}\right)$ & $24.0(17.5-26.0)$ & 24.0 & 24.0 & 17.5 & 20.7 & 25.4 & 21.4 & 26.0 \\
\hline $\operatorname{BSA}\left(\mathrm{m}^{2}\right)$ & $1.5(1.4-1.7)$ & 1.6 & 1.5 & 1.5 & 1.5 & 1.4 & 1.5 & 1.7 \\
\hline \multicolumn{9}{|l|}{ Duration (months) } \\
\hline Follow-up & $10.0(3.0-32.0)$ & 32.0 & 20.0 & 20.0 & 10.0 & 10.0 & 9.0 & 3.0 \\
\hline Event-free $^{\mathrm{a}}$ & $10.0(3.0-25.0)$ & 25.0 & 20.0 & 14.0 & 10.0 & 10.0 & 8.0 & 3.0 \\
\hline$K t / V$ value & $1.4(1.2-1.5)$ & 1.5 & 1.4 & 1.5 & 1.4 & 1.4 & 1.2 & 1.4 \\
\hline \multicolumn{9}{|l|}{ Flow rates (ml/minute) } \\
\hline First month & $205.0(203.3-236.7)$ & 236.7 & - & 205.0 & 206.7 & 205.0 & 203.3 & - \\
\hline Third month & $266.7(203.3-276.7)$ & 263.3 & - & 276.7 & 270.0 & 203.3 & 253.3 & 276.7 \\
\hline \multicolumn{9}{|l|}{ Dialysis venous pressure $(\mathrm{mmHg})$} \\
\hline First month & $128.0(108.3-178.0)$ & 108.3 & - & 178.0 & 128.0 & 140.3 & 113.3 & - \\
\hline Third month & $131.0(116.7-148.7)$ & 116.7 & - & 131.0 & 146.7 & 148.7 & 120.3 & 131.0 \\
\hline Peak systolic velocity (cm/second) & $384.5(335.0-551.0)$ & 350.0 & - & 370.0 & 551.0 & 335.0 & 399.0 & 465.0 \\
\hline \multicolumn{9}{|l|}{ Peak systolic velocity ratios } \\
\hline Artery-graft junction & $2.1(1.4-2.4)$ & 2.4 & - & 1.6 & 2.1 & 1.4 & 2.2 & - \\
\hline Vein-graft junction & $3.0(2.3-3.8)$ & 3.0 & - & 2.8 & 3.8 & 2.3 & 3.3 & - \\
\hline
\end{tabular}

M, male; F, female; BMI, body mass index; BSA, body surface area; $K t / V,\left(K_{\text {urea }} \times t_{\mathrm{d}}\right) / V_{\text {urea }}$; B, brachial artery; DB, connected between deep brachial vein and brachial artery.

Dash indicates no data available.

${ }^{a}$ Event was defined as the occurrence of any acute complication: stenosis, thrombosis, or malfunction requiring intervention during the follow-up period.

TABLE 2. Grading of factors and complications

\begin{tabular}{|c|c|c|c|c|c|c|c|c|}
\hline & \multirow[b]{2}{*}{$N(\%)$} & \multicolumn{7}{|c|}{ Patient no. } \\
\hline & & 1 & 2 & 3 & 4 & 5 & 6 & 7 \\
\hline \multicolumn{9}{|l|}{ Factors affecting outcomes } \\
\hline Previous procedures same limb & $7(100.0)$ & 1 & 3 & 2 & 1 & 2 & 3 & 1 \\
\hline Tobacco use & $2(28.6)$ & 0 & 0 & 0 & 1 & 0 & 0 & 1 \\
\hline Pulmonary status & $2(28.6)$ & 0 & 0 & 0 & 0 & 2 & 2 & 0 \\
\hline Carotid disease & $2(28.6)$ & 0 & 0 & 0 & 0 & 3 & 0 & 3 \\
\hline Cardiac status & $5(71.4)$ & 0 & 1 & 0 & 1 & 2 & 1 & 1 \\
\hline Diabetes & $3(42.9)$ & 2 & 0 & 3 & 0 & 0 & 2 & 0 \\
\hline Hypertension & $7(100.0)$ & 1 & 2 & 3 & 1 & 1 & 2 & 1 \\
\hline Hyperlipemia & $5(71.4)$ & 0 & 2 & 0 & 2 & 2 & 1 & 2 \\
\hline \multicolumn{9}{|l|}{ Complications } \\
\hline Stenosis & $5(71.4)$ & 2 & 0 & 2 & 1 & 0 & 2 & 2 \\
\hline Hematoma & $1(14.3)$ & 0 & 0 & 0 & 1 & 0 & 0 & 0 \\
\hline Thrombosis & $3(42.9)$ & 3 & 0 & 0 & 0 & 0 & 2 & 2 \\
\hline Neuropathy & $3(42.9)$ & 1 & 0 & 1 & 0 & 1 & 0 & 0 \\
\hline
\end{tabular}

Value indicates grading in each category according to the reporting standards of the Society for Vascular Surgery/American Association for Vascular Surgery.

tion. With the reverse-loop graft, patients were easyto-needle, and adequate dialysis was achieved.

Good surgical practice requires that a venous graft be placed as distal as possible to permit future access to more proximal segments of the vein if necessary $(6,8)$. In general, a peripheral-to-central sequence of fistulae construction should be envisioned. In the absence of suitable superficial veins, many authors recommend the basilic vein for autogenous brachiobasilic arteriovenous fistula construction before considering the placement of a prosthetic AVG (9). However the 1-year primary patency rate varies widely, with reported rates as low as $23 \%(10)$ and as high as $82 \%$ (3). In addition, the need for transposition or superficialization of the basilic vein may not be feasible if the vessels are deemed to be too fragile at the initial operation. Furthermore, a second operation may be necessary to superficialize the basilica vein. It is inevitable that some patients will ultimately require AVG placement in the upper arm. However, the current practice of placing the AVG in the conventional configuration results in wasting a significant length of the upper arm vessels and limits the number of potential sites for future vascular access. The reverse-loop design was intended to address this issue.

The clinical outcomes of the reverse-loop upper arm AVGs in the present series demonstrated few complications. Patients were able to achieve an adequate dialysis dose with access in the reverse-loop configuration. Thrombosis was the most prevalent complication and accounted for most of the follow-up interventions and 
loss of access. Surgical revision could be easily performed either by patching the junction or by connecting the outflow portion of the graft to a more proximal site on the vein with a new anastomosis. Most importantly, we demonstrated that a new AVG could be created on the same arm as a sufficient length of proximal vessel was preserved. The $100 \%$ patency at a median follow-up duration of 10 months in our series suggests that the patency rate of the reverse-loop AVG is at least as good as an autogenous brachiobasilic arteriovenous fistula $(3,10)$ or an AVG in the conventional position $(1,3)$.

An acute-angled configuration of the AVG may result in turbulent flow at the graft-vessel junction. Such turbulent flow is considered a risk for intimal hyperplasia (11) and remains the most frequent cause of AVG stenosis $(12,13)$. In the reverse-loop configuration, an acute angle of $<90$ degrees at the arterial anastomosis is also associated with less graft dysfunction (14). With duplex scan criteria for AVG stenosis (15), no significant stenosis was found in four out of six AVG scans in our case series. Given the acute angle at the graft-vein junction, stenosis occurring at a certain configuration may render it unsuitable for treatment with angioplasty (12). In our experience, the relatively acute angle of the graft-vessel junction did not prohibit endovascular angioplasty.

The limitations of this initial experience include a small number of cases, the retrospective study design, and the absence of a direct clinical comparison with autogenous brachiobasilic upper arm transposition or brachial-axillary AVGs in the conventional configuration. In the era of a "fistula first" strategy, all options to maximize venous real estate should be considered. By placing an AVG using the reverse-loop configuration, an autogenous brachiobasilic arteriovenous fistula could still potentially be created later because the basilic vein is preserved (16). We have yet to explore such an option in this cohort of patients. The value of preserving venous real estate using the reverse-loop AVG would also be consistent with the strategy of creating a secondary fistula for the patient, thus maximizing vascular access options (17).

In conclusion, a reverse-loop upper arm AVG is an effective and feasible option for uremic patients with compromised forearm vessels, who have no option other than the placement of AVGs. This novel approach conserves most of the upper arm vessels for potential future access and includes the possibility of the creation of a brachiobasilic arteriovenous fistula at a later stage. The graft is comparatively easy to repair either surgically or endovascularly. Further study is needed to determine the hemodynamic and clinical significance of acuteangled configuration of graft-vessel anastomoses.

\section{Sources of Funding}

None.

\section{References}

1. Huber TS, Carter JW, Carter RL, Seeger JM: Patency of autogenous and polytetrafluoroethylene upper extremity arteriovenous hemodialysis accesses: a systematic review. J Vasc Surg 38:1005-1011, 2003

2. Weale AR, Bevis P, Neary WD, Lear PA, Mitchell DC: A comparison between transposed brachiobasilic arteriovenous fistulas and prosthetic brachioaxillary access grafts for vascular access for hemodialysis. J Vasc Surg 46:997-1004, 2007

3. Kakkos SK, Andrzejewski T, Haddad JA, Haddad GK, Reddy DJ, Nypaver TJ, Scully MM, Schmid DL: Equivalent secondary patency rates of upper extremity Vectra vascular access grafts and transposed brachial-basilic fistulas with aggressive access surveillance and endovascular treatment. J Vasc Surg 47:407-414, 2008

4. Jean-Baptiste E, Hassen-Khodja R, Haudebourg P, Declemy S, Batt M, Bouillanne PJ: Axillary loop grafts for hemodialysis access: midterm results from a single-center study. J Vasc Surg 47:138-143, 2008

5. Sidawy AN, Gray R, Besarab A, Henry M, Ascher E, Silva Jr M, Miller A, Scher L, Trerotola S, Gregory RT, Rutherford RB, Kent KC: Recommended standards for reports dealing with arteriovenous hemodialysis accesses. J Vasc Surg 35:603-610, 2002

6. III. NKF-K/DOQI Clinical Practice Guidelines for Vascular Access: update 2000 Am J Kidney Dis 37:S137-S181, 2001

7. Rutherford RB, Baker JD, Ernst C, Johnston KW, Porter JM, Ahn S, Jones D: Recommended standards for reports dealing with lower extremity ischemia: revised version. J Vasc Surg 26:517-538, 1997

8. Harland RC: Placement of permanent vascular access devices: surgical considerations. Adv Ren Replace Ther 1:99-106, 1994

9. Fitzgerald JT, Schanzer A, Chin AI, McVicar JP, Perez RV, Troppmann $\mathrm{C}$ : Outcomes of upper arm arteriovenous fistulas for maintenance hemodialysis access. Arch Surg 139:201-208, 2004

10. Wolford HY, Hsu J, Rhodes JM, Shortell CK, Davies MG, Bakhru A, Illig KA: Outcome after autogenous brachial-basilic upper arm transpositions in the post-National Kidney Foundation Dialysis Outcomes Quality Initiative era. J Vasc Surg 42:951-956, 2005

11. Haruguchi $\mathrm{H}$, Teraoka S: Intimal hyperplasia and hemodynamic factors in arterial bypass and arteriovenous grafts: a review. J Artif Organs 6:227-235, 2003

12. Kanterman RY, Vesely TM, Pilgram TK, Guy BW, Windus DW, Picus D: Dialysis access grafts: anatomic location of venous stenosis and results of angioplasty. Radiology 195:135-139, 1995

13. Lemson S, Tordoir JH, Ezzahiri R, Leunissen KM, Kitslaar PJ, Hoeks AP: Hemodynamics of venous cuff interposition in prosthetic arteriovenous fistulas for hemodialysis. Blood Purif 20:557-562, 2002

14. Rosas SE, Joffe M, Burns JE, Knauss J, Brayman K, Feldman HI: Determinants of successful synthetic hemodialysis vascular access graft placement. J Vasc Surg 37:1036-1042, 2003

15. Dumars MC, Thompson WE, Bluth EI, Lindberg JS, Yoselevitz M, Merritt CR: Management of suspected hemodialysis graft dysfunction: usefulness of diagnostic US. Radiology 222:103-107, 2002

16. Keoghane SR, Leow CK, Gray DW: Routine use of arteriovenous fistula construction to dilate the venous outflow prior to insertion of an expanded polytetrafluoroethylene (PTFE) loop graft for dialysis. Nephrol Dial Transplant 8:154-156, 1993

17. Asif A, Unger SW, Briones P, Merrill D, Cherla G, Lenz O, Roth D, Pennell P: Creation of secondary arteriovenous fistulas: maximizing fistulas in prevalent hemodialysis patients. Semin Dial 18:420-424, 2005 